\title{
Moisture Capacity: Definition, Measurement, and Application in Determining the Optimal Water Content in Granulating
}

\author{
Xuewei $\mathrm{LV}^{, 1)}$ Chenguang $\mathrm{BAI}^{2}{ }^{2)}$ Guibao $\mathrm{QIU},{ }^{2)}$ Shengfu $\mathrm{ZHANG}^{2)}$ and Meilong $\mathrm{HU}^{2)}$ \\ 1) Ph.D Student, School of Materials Science and Engineering, Chongqing University, Chongqing 400044 China. \\ E-mail: Ivxuewei@163.com \\ 2) School of Materials Science and Engineering, Chongqing University, Chongqing 400044 \\ China. E-mail: bguang@cqu.edu
}

(Received on December 21, 2009; accepted on March 15, 2010)

\begin{abstract}
The optimal granulation moisture, which means the least water content added into the mixture for obtaining suitable size distribution of the granules, is of vital importance for sintering. The moisture capacity, which means the maximum water content held in the iron ores of unit mass, is suggested, and defined. An apparatus for the moisture capacity measurment was developed. Five samples were selected for the measurments. In order to study the relationship between the moisture capacity and some characters of iron ores, the surface area and pore volume was measured by the method of liquid nitrogen absorption. It was found that the moisture capacity increaseed with increasing the external surface area of the iron ore, and decreased with increasing the pore volume in the iron ores. The iron ores were granluted with various water content level in the labtotary rotaing drum, and then loaded in the sintering pot for measuring the permeability of the burden. The size distribution of the granules were also measured for asisting confirming the optimal water content in granlation. The application of moisture capacity indicated that the iron ore of high moisture capacity needed more water added in the granulation process to get high permeability.
\end{abstract}

KEY WORDS: granulation; moisture capacity; iron ore; surface area; permeability.

\section{Introduction}

The sintering process consist, in essence, of mixing moisture, iron ore fines and other fines materials with solid fuel, normally coke breeze, and loading the mix on to a permeable grate. The upper surface is raised to a high temperature by oil or gas burners and air is drawn downwards through the grate. After a short ignition period, heating of the bed top is discontinued and a narrow combustion zone move downwards through the bed, each layer in turn being heated to about $1300^{\circ} \mathrm{C}$. In the combustion zone, bonding takes place between the grains and strong agglomerate is formed. Customarily, the first stage of the whole procedure, namely, spraying water on to iron ore fines and the subsequent tumbling, is called granulating.

In the course of granulation, the agglomerates undergo a continuous gradual compaction, at least in the initial period of growth. As a result, the void spaces become increasingly filled with liquid. Newitt and Jones ${ }^{1)}$ and Rumpf ${ }^{2)}$ have formulated the wet pellet strength in term of three-phase air-liquid-solid and two-phase liquid-solid regimes of the particulate ensemble, which is shown as Fig. 1. As for the granulation of iron ore sintering, the regime of pendular is the suitable statues for water content.

The iron ore and other particles held together by a liquid bridge. As shown in Fig. 2, two forces contribute to the tensile strength of the bond in an additive fashion; the pull due to surface tension at solid-liquid-gas contract line directed along the liquid surface and the negative capillary pressure existing in the liquid bridge. Generally speaking, the strength of the granules increases with increasing the water content during granulation. However, more water means more energy consumption. The calculation for this balance relation is shown in Fig. 3, in which the strength of granule
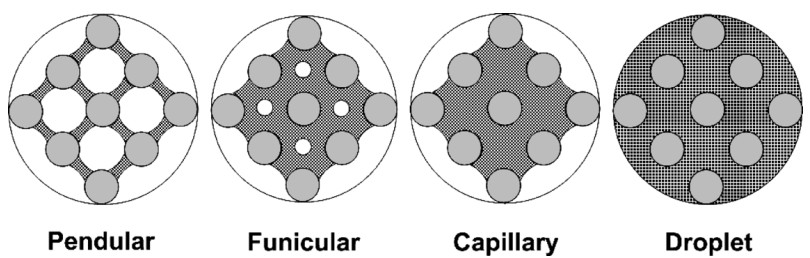

Fig. 1. Three-phase air-liquid-solid and two phase liquid-solid regimes of a particulate ensemble

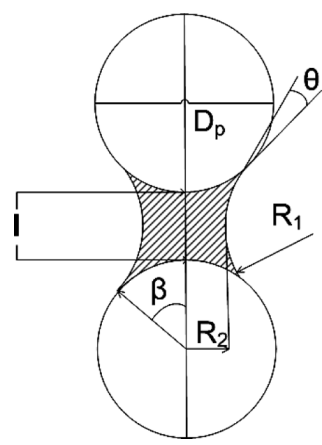

Fig. 2. Pendular bonded between two spheres. 
(A)

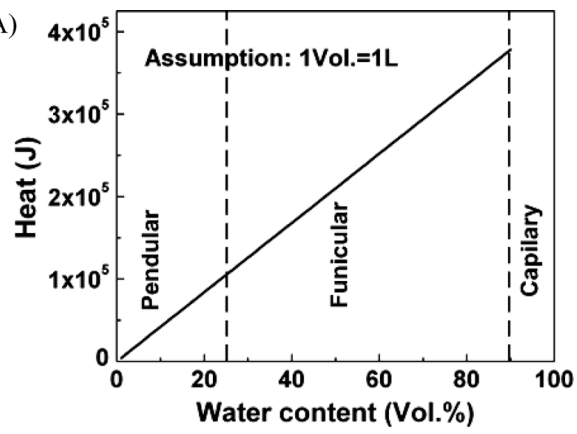

(B)

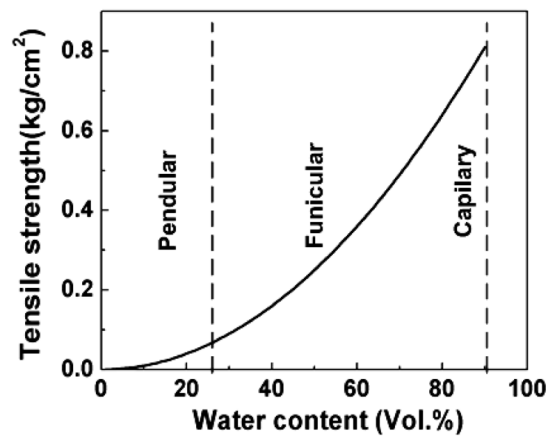

Fig. 3. Relationship between the water content and granule strength or energy consumption.

is calculated based on the model ${ }^{3)}$ shown in Fig. 2 and only considering the energy consumption for water evaporation by heating from the room temperature. The optimal water content is of vital importance for the sintering plant saving energy consumption and remaining the required quality of iron ore sinter simultaneously. Many studies ${ }^{4-9)}$ were carried out on the optimal water content in the granulating, most of them focused on the granulating experiments, and some studied the contact behavior between the water and ores. $^{6-8,10-12)}$ Recently, Litster ${ }^{10-12)}$ studied a lot on the interaction mechanism between the water and iron particle and the growth kinetic of the granules. However, little study introduced a simple and useful method to measure or predict the optimal moisture content during the granulating. In present study, a moisture capacity of iron ore fines was defined and measured with a novel and simple method, the relationship between the moisture capacity with some other characters of iron ore fines were discussed.

\section{Method for Moisture Capacity}

\subsection{Definition of Moisture Capacity}

Moisture capacity, in present study, is defined as the maximum water content which can be hold among the iron ore particles of unit mass. ${ }^{13)}$ The equation used to calculate the moisture capacity can be expressed as:

$$
m c=\left(M_{w} / M_{i}\right) \times 100 \% \text {. }
$$

where $m c, M_{w}$, and $M_{i}$, individually, refer to the moisture capacity, mass of water absorbed by the bulk, and the mass of iron ores. The water which touches the particles of iron ore can be absorbed into the bulk of iron ore and moves among the particles under the capillary pressure. Therefore, the bulk density or the packing conditions will influence the total water content. The water hold among the particles can also be absorbed into the pores of the particles. Therefore,

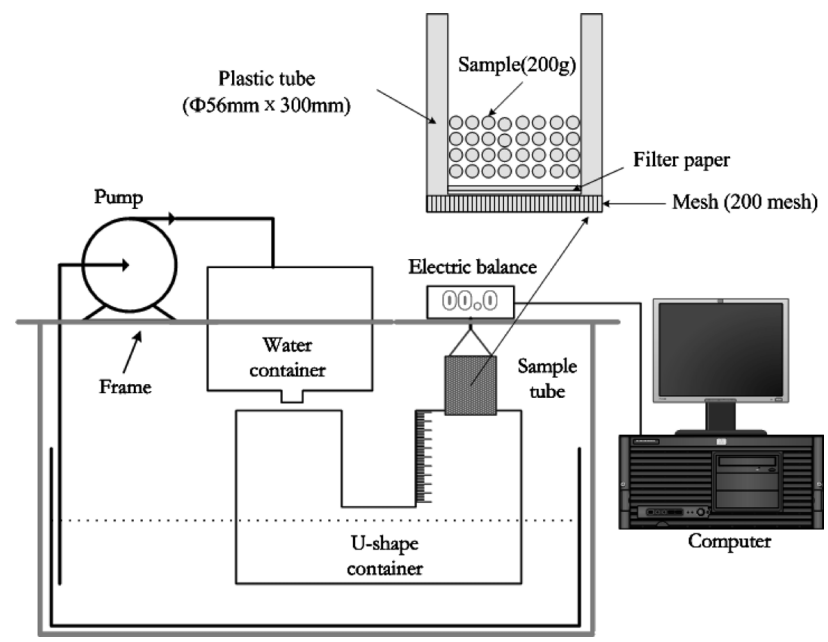

Fig. 4. Schematic of instrument for measurement of moisture capacity.

the porosity of the particles has a great effect on the moisture capacity.

\subsection{Equipment}

The measurement of moisture capacity of the iron ore fines were carried out in the self-made instrument which is schematically shown in Fig. 4. The iron ore fines are loaded in the sample tube, which is with a diameter of $56 \mathrm{~mm}$ and a length of $300 \mathrm{~mm}$, and hanged to an electric balance. There is a sieve covered at the end of the tube. A piece of filter paper, which is used to avoid the leaking of the very small iron ore fine into the U-shape container through the sieve, is put at the bottom of the sample tube and immerged into the water for a moment before the measurement. The sample tube is taken out for loading the samples after the filer paper is saturated with water, and then hanged to the electric balance. The water in the U-shape container is absorbed into the sample, resulting in an increase of reading on the electric balance.

\subsection{Procedure}

The iron ore fines need to dry at $120^{\circ} \mathrm{C}$ for $4 \mathrm{~h}$ in a drying chamber to remove the original water before measurements. The size distribution of the iron ore fines dried are measured through a series of screens which are classified as $0.2 \mathrm{~mm}, 0.7 \mathrm{~mm}, 1 \mathrm{~mm}, 3 \mathrm{~mm}, 5 \mathrm{~mm}, 8 \mathrm{~mm}$, and $10 \mathrm{~mm}$. The iron ore fines of $200 \mathrm{~g}$ are naturally loaded in the sample tube. The pressing is not allowed during the loading. The sample tube needs to be immerged into the water for absorbing. Two forces affect the accuracy of the measurement. One force is the buoyancy, which is expressed by:

$$
f=\rho \cdot \pi \cdot \gamma \cdot D^{2} \cdot h / 4
$$

where $h$ is the immerging depth, $D$ is the diameter of the tube, and $\rho$ is the density of the water.

The other is the interfacial tension between the water and tube, which are shown in Fig. 5, expressed by:

$$
F=\pi \cdot D \cdot \cos \theta \cdot \sigma
$$

where $\sigma$ is the surface tension of the water, and $\theta$ is the contact angle between the water and the tube.

The immerged depth of the tube can be calculated by Eq. 
(4) when the two force balance.

$$
h=\frac{4 \cdot \cos \theta \cdot \sigma}{\rho \cdot g \cdot D}=\frac{4 \cdot \cos 20^{\circ} \cdot 72.75}{1000 \cdot 9.8 \cdot 0.056}=0.49 \mathrm{~mm}
$$

In present study, $h$ was calculated as $0.49 \mathrm{~mm}$. Put down the tube $0.49 \mathrm{~mm}$ under the water, making the balance between the buoyancy of sample tube and the interfacial tension. Therefore, the reading is just the mass of water absorbed into the sample.

\section{Experimental}

\subsection{Samples}

Five kinds of iron ores will be used in this study. The chemical composition and the size distribution of these five ores are listed in Tables $\mathbf{1}$ and $\mathbf{2}$ individually. In the industrial practice, several iron ores are used together for the metallurgical and economic reasons. In present study, the fives mixtures, which are made of these five iron ores, return fines, coke, and flux with various ratios, were used to find the relationship between moisture capacity of the mixture and the optimal water content. The mass fractions of the mixture studied are listed in Table 3.

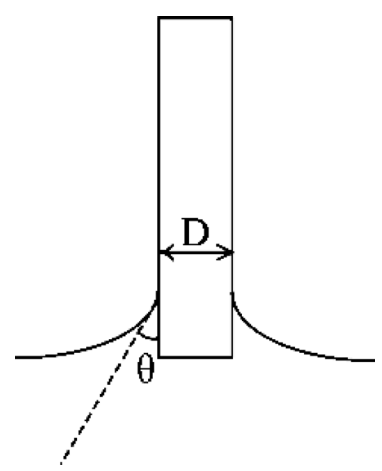

Fig. 5. Schematic diagram of interfacial tension.

\subsection{Granulation and Permeation Test}

The granulation experiments of iron ore will be carried out in the laboratory rotaing mixer at a defined rotating rate for $3 \mathrm{~min}$ with various water content added. The rotaing mixer is with a diameter of $600 \mathrm{~mm}$ and a length of $1200 \mathrm{~mm}$. The particle distribution of the granules was measured using a series of sieves, including $0.2,0.7,1,3,5$, $8,10 \mathrm{~mm}$. The granules were loaded into the laboratory sintering pot, which is with a diamter of $200 \mathrm{~mm}$ and a height of $1000 \mathrm{~mm}$. The negative pressure of the burden in the sintering pot under a defined gas flow rate was measured to represent the permeability of the burden.

The moisture capacity was defined for the maximum of the water content hold in the iron ore particles. However, the flux, fuel, and the sinter return are all used in the granulation. In order to give a reasonable explanation of the granulation in practice, the definition of moisture capacity is expanded to the fuel and coal. As for the flux, the moisture capacity of the limestone, dolomite can be measured easily. However, the moisture capacity of lime is very difficult to get an accurate value. The chemical reaction between the water and lime happens during the measurements, which is exothermic, resulting in the evaporation of the water. Therefore the water will be consumed in reaction, evaporation, and physical absorption, great error creating during the measurements. In order to diminish the effect of lime, the water will be first added into the lime for slaking. The experience indicates that the suitable water added is $60 \%$ of lime in mass. Several water content levels were selected for granulation and the negative pressure of the granules in the sintering pot were measured to compare the permeability. The water content with the lowest negative pressure of the burden is the optimal water content for granulation.

\subsection{BET Porosometry}

In order to study the dependency of the moisture capacity on the surface area, particle size, and the pore volume of

Table 1. Composition of the five iron ores selected (mass $\%$ ).

\begin{tabular}{llllllllllll}
\hline Ore & $\mathrm{LOI}$ & $\mathrm{TFe}$ & $\mathrm{FeO}$ & $\mathrm{SiO}_{2}$ & $\mathrm{CaO}$ & $\mathrm{MgO}$ & $\mathrm{A}_{2} \mathrm{O}_{3}$ & $\mathrm{MnO}$ & $\mathrm{TiO}_{2}$ & $\mathrm{~S}$ & $\mathrm{P}$ \\
\hline $\mathrm{I}$ & 0.46 & 66.7 & 0.90 & 3.01 & 0.20 & 0.21 & 0.61 & 0.27 & 0.36 & 0.035 & 0.048 \\
II & 0.64 & 64.4 & 20.7 & 5.36 & 0.50 & 0.43 & 1.81 & 0.39 & 0.82 & 0.208 & 0.086 \\
III & 0.49 & 66.2 & 0.51 & 3.32 & 0.10 & 0.07 & 0.91 & 0.25 & 0.40 & 0.023 & 0.059 \\
$\mathrm{IV}$ & 1.32 & 63.6 & 0.38 & 4.54 & 0.10 & 0.14 & 2.32 & 0.28 & 0.55 & 0.021 & 0.052 \\
V & 2.76 & 63.0 & 0.77 & 3.81 & 0.20 & 0.07 & 2.22 & 0.21 & 0.81 & 0.046 & 0.070 \\
\hline
\end{tabular}

Table 2. Size distribution of iron ores (mass $\%$ ).

\begin{tabular}{lrrrrrrrr}
\hline Ore & $>10 \mathrm{~mm}$ & $8-10 \mathrm{~mm}$ & $5-8 \mathrm{~mm}$ & $3-5 \mathrm{~mm}$ & $1-3 \mathrm{~mm}$ & $0.7-1 \mathrm{~mm}$ & $0.2-0.7 \mathrm{~mm}$ & $<0.2 \mathrm{~mm}$ \\
\hline I & 3.75 & 0.14 & 1.09 & 2.13 & 3.10 & 1.19 & 6.57 & 82.04 \\
II & 0.13 & 0.00 & 0.47 & 0.98 & 1.61 & 0.48 & 3.11 & 93.22 \\
III & 6.92 & 2.10 & 18.98 & 14.43 & 10.88 & 4.69 & 6.43 & 35.58 \\
IV & 6.23 & 2.74 & 14.58 & 14.40 & 18.14 & 8.59 & 15.21 & 20.11 \\
V & 0.39 & 0.78 & 12.24 & 14.51 & 23.16 & 10.25 & 19.84 & 18.84 \\
\hline
\end{tabular}

Table 3. Mass fraction of raw materials in the five mixtures (mass\%).

\begin{tabular}{cccccccccc}
\hline Mixtures & I & II & III & IV & V & return & coke & lime & dolomite \\
\hline A & 6.24 & 6.24 & 15.60 & 9.36 & 24.96 & 25.00 & 4.13 & 3.48 & 5.00 \\
B & 6.24 & 6.24 & 12.47 & 9.36 & 28.07 & 25.00 & 4.13 & 3.50 & 5.00 \\
C & 6.24 & 6.24 & 12.48 & 6.24 & 31.21 & 25.00 & 4.13 & 3.45 & 5.00 \\
D & 6.24 & 6.24 & 9.36 & 6.24 & 34.32 & 25.00 & 4.13 & 3.47 & 5.00 \\
E & 3.12 & 6.23 & 9.35 & 6.23 & 37.41 & 25.00 & 4.13 & 3.52 & 5.00 \\
\hline
\end{tabular}


the iron ore were also measured. The particle features like surface area were measured by ASAP2020 produced by Micromeritics ${ }^{\circledR}$. ASAP 2020 is the equipment designed by Micromeritics, which can obtain the high-quality data of surface area and porosity of the materials. The principle of the ASAP 2020 is the adsorption of nitrogen at low temperature, the mass of nitrogen absorbed can be measured, thus, the surface area can be calculated with this data based on the theoretical absorption model. The pore size distribution can be calculated based on the theory of capillary condensation, which means the "process by which multilayer adsorption from the vapor into a porous medium proceeds to the point at which pore spaces become filled with condensed liquid from the vapor". ${ }^{14)}$ All the iron ores were measured using the nitrogen at the temperature of $77 \mathrm{~K}$.

\section{Results and Discussions}

The moisture capacities and the saturation time (Ts) of the five iron ores, fuel, and the flux are listed in Table 4. It shows that coal has a greatest moisture capacity. Return sinter has a least value for its less surface area and relative big particle. For the ores, ore $\mathrm{V}$ has a greater moisture capacity, and ore I has a less moisture capacity.

The surface area and the pore volume $\left(V_{\text {pore }}\right)$ of the iron ores are listed in Table 5. The Isotherm linear plots of five ores are given in Fig. 6. All the plots are similar, belong pattern III based on the theory of adsorption. ${ }^{15)}$ The materials of pattern III can absorb more nitrogen at high pressure. Multiple layers of adsorption happens to this materials, therefore BET model in Table 5 should be more accurate than Langmuir model. Ores II and III have small surface area, from 2 to $5 \mathrm{~m}^{2} / \mathrm{g}$, ore I, IV and V have large surface area, from 9 to $30 \mathrm{~m}^{2} / \mathrm{g}$. The microspore area and external area $\left(S_{\mathrm{E}}\right)$ are also shown in Table 5. The microspore area only refers to the pore inside the iron ore particles, and the external area refers to the outside of the particles. It shows that ore I has a greatest microspore surface area, about $5.35 \mathrm{~m}^{2} / \mathrm{g}$, and ore $\mathrm{V}$ is the second ore with greater microspore surface area. Ore II has little microspore surface area, only $0.07 \mathrm{~m}^{2} / \mathrm{g}$. Ore III and IV have very similar value of microspore surface area, about 1.19 and $1.81 \mathrm{~m}^{2} / \mathrm{g}$. For the external surface area, the order of the ore from great to little is ore V, I, IV, III and II. Figure 7 shows the pore volume distribution with the pore width for the five ores. It is

Table 4. Moisture capacity and saturation time of iron ores.

\begin{tabular}{lcccccccc}
\hline & \multicolumn{9}{c}{ Ores } & & Fuel & Flux \\
& I & II & III & IV & V & Return & coals & dolomite \\
\hline Mc (\%) & 10.6 & 16.3 & 12.8 & 14.4 & 17.5 & 8.9 & 41.0 & 16.0 \\
Ts (s) & 150 & 130 & 100 & 300 & 40 & 110 & 375 & 120 \\
\hline
\end{tabular}

indicated that ore I, IV, and V have great pore volume, and ore II and III have small pore volume. Table 5 shows that ore I should have the greatest pore volume, but the distribution curve of ore I in Fig. 8 is always under the curves of ore IV and V. It seems wrong, but actually right. The reason is that the upper width of ore I is much bigger by $16 \mathrm{~nm}$ than ore $\mathrm{V}$, which is not very obvious in Fig. 7 with a logarithmic $\mathrm{X}$-axes.

The dependency of the moisture capacity on the external surface area and the pore volume was studied by using the measurements. The correlation got was as follows:

$$
M c=13.7+0.374 \times S_{\mathrm{E}}-2896 \times V_{\text {por }}
$$

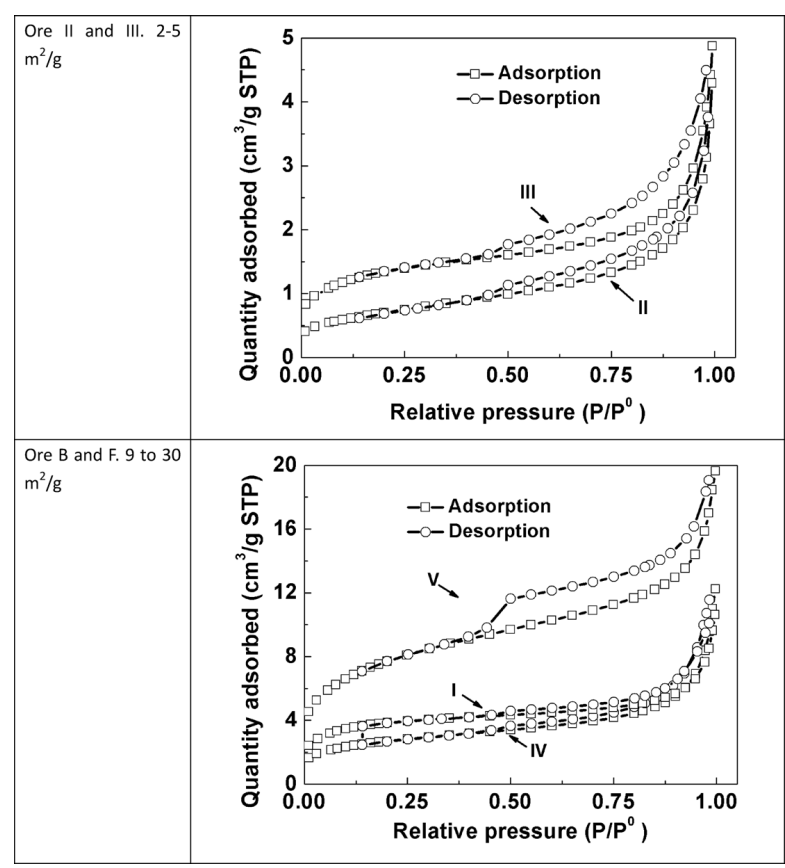

Fig. 6. Isotherm linear plot of ores obtained by ASAP 2020.

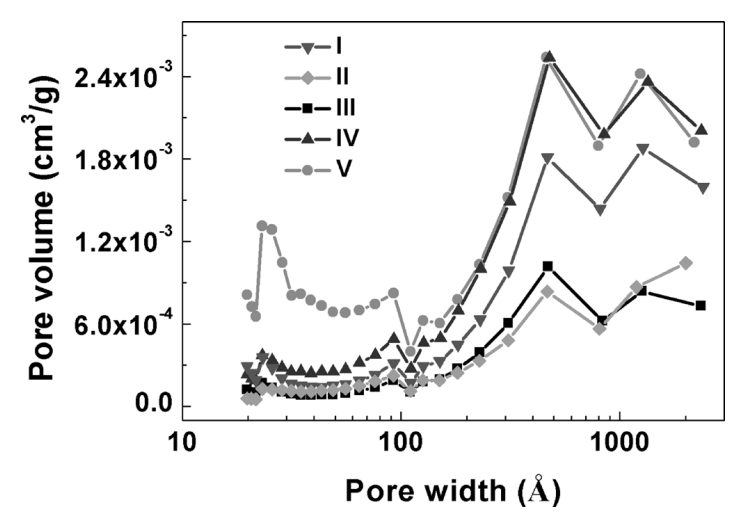

Fig. 7. Pore volume verse pore width obtained by ASAP 2020.

Table 5. Surface area and pore feature of the iron ore.

\begin{tabular}{llllll}
\hline Surface area $\left(\mathrm{m}^{2} / \mathrm{g}\right)$ & $\mathrm{I}$ & II & III & IV & V \\
\hline BET model & 13.59 & 2.55 & 4.79 & 9.70 & 27.85 \\
Langmuir model & 18.50 & 3.58 & 6.61 & 13.41 & 38.34 \\
Microspore area & 5.35 & 0.07 & 1.19 & 1.81 & 4.74 \\
External area $\left(\mathrm{S}_{\mathrm{E}}\right)$ & 8.22 & 2.48 & 3.60 & 7.89 & 23.10 \\
\hline Pore feature & $\mathrm{I}$ & $\mathrm{II}$ & $\mathrm{III}$ & $\mathrm{IV}$ & V \\
\hline Pore volume $\left(\mathrm{cm}^{3} / \mathrm{g}\right)\left(\mathrm{V}_{\text {Pore }}\right)$ & $2.3 \mathrm{E}-3$ & $2 \mathrm{E}-6$ & $4.9 \mathrm{E}-4$ & $7.1 \mathrm{E}-4$ & $1.7 \mathrm{E}-3$ \\
Pore size $(\mathrm{A})$ & 48.36 & 104.01 & 62.91 & 77.98 & 43.61 \\
\hline
\end{tabular}




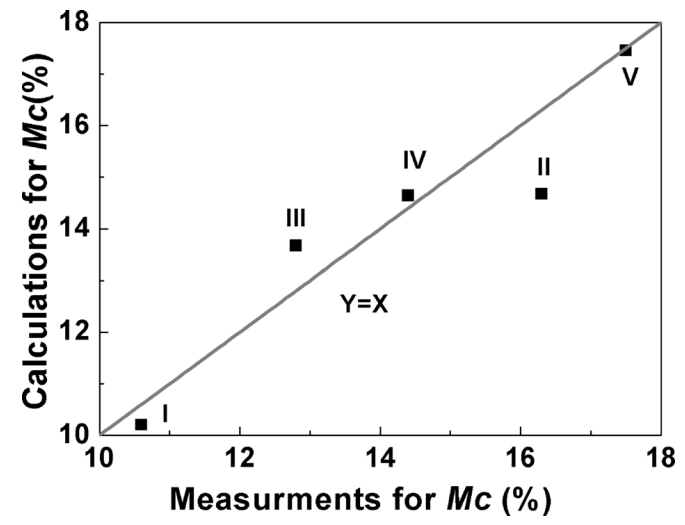

Fig. 8. Measurements verse calculation for moisture capacity.

Table 6. Moisture capacity and saturation time for the mixture.

\begin{tabular}{lccccc}
\hline & A & B & C & D & E \\
\hline Mc (\%) & 16.5 & 16.25 & 14.85 & 15.4 & 17.25 \\
Ts (s) & 80 & 55 & 240 & 200 & 30 \\
\hline
\end{tabular}

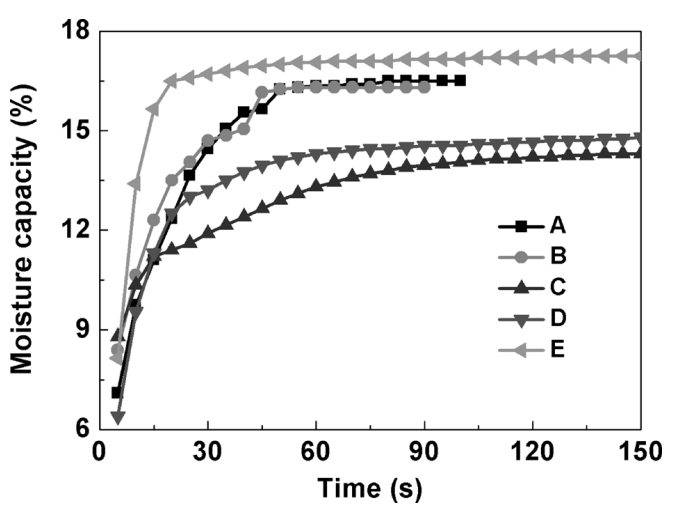

Fig. 9. Water content absorbed as a function of time.

where $S_{\mathrm{E}}$ and $V_{\text {pore }}$ are the external surface area and pore volume. The values calculated and the measurements for the five samples are plotted in Fig. 8, from which it is indicated the calculation agree well with the measurements. Equation (5) indicate that the moisture capacity increase with increasing the external surface area of the iron ore, and decreases with increasing the pore volume in the iron ores. Generally speaking, the iron ore of small size has the great surface area. Equation (5) also means the iron ore particle of small size has a big moisture capacity. This conclusion agree well with the previous study. ${ }^{13)}$

The moisture capacity of the five mixtures of iron ores, fuels, return fines, and the flux are listed in Table 6. The kinetic of water absorbed into the mixtures are plotted in Fig. 9. Mixture $\mathrm{E}$ has high moisture capacity and mixture $\mathrm{C}$ has low moisture capacity. The moisture capacities of mixture $\mathrm{A}$ and $\mathrm{B}$ are very close to each other, and the water absorbed curves are also very similar. The time for water saturation in these five mixtures are different. The saturation time for mixture $\mathrm{E}$ is the shortest, only $30 \mathrm{~s}$, while that for mixtures A and B are longer than mixture E, about 50-90 s; and that for mixtures $\mathrm{C}$ and $\mathrm{D}$ are longest, about more than $200 \mathrm{~s}$. It means that mixtures A, B, and E have enough time to absorb the water for saturation, while mixture $\mathrm{C}$ and $\mathrm{D}$ can be very close to saturation.

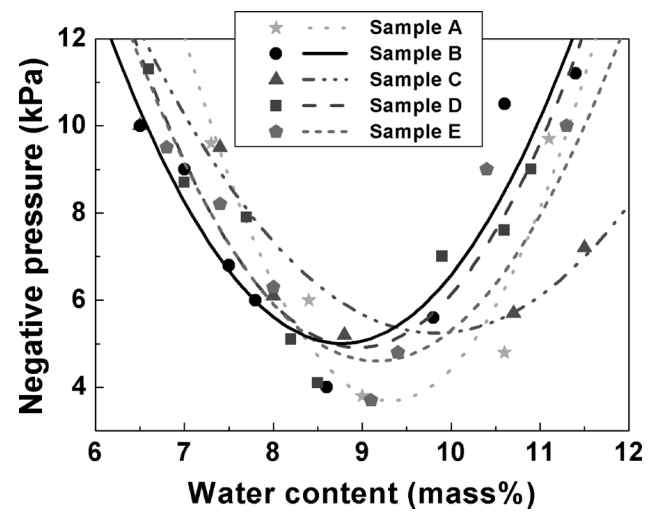

Fig. 10. Negative pressure of burden as a function of water content.

The Relationship between the negative pressure of the burden and the water content added for the five iron ores are plotted in Fig. 10. From Fig. 10, it is indicated that the permeability of the burden in the sintering pot increases with increasing the water content added during the granulation first, a maximum permeability, meaning the minimum negative pressure during the suction measurement, will reach at suitable water content, then the permeability decreases with increasing the water content. The relationship between the permeability of the iron ore burden in the sintering pot and the water content added in the mixture, which is similar to a parabola curve, got in present study agrees with the previous reports. ${ }^{16,17)}$ The optimal water content was decided according to these measurements, and the results are listed in Table 7. The rules for this decision are described as follows: the water content with the minimum negative pressure from the fitting curves is the optimal value if the square of correlation coefficient between the measurements and the fitting curve is above 0.8 , or else it is below 0.8 , the water content with the minimum negative pressure in the measurements is selected to instead the optimal value.

The particle distribution of the granules with various water contents are plotted in Fig. 11. The mass fractions of the particles with defined size were represented with histograms, and the negative pressure of the burden in the sintering pot as a function of water content added were also plotted together for easily comparing the suitable size distributions. Figure 11 indicate that the iron ore granule grows up with increasing the water content added into the mixtures. The mass fraction of the particles with small size decreases with increasing the water content, and that of particles with big size increase with increasing the water content. Summarizing the five figures, it was indicated that the mass fraction of the particle with $<0.2,0.2-0.7,0.7-1 \mathrm{~mm}$ decreases with increasing the water content added into the mixtures, while that of particles with $1-3,3-5,5-8,8-10$ $\mathrm{mm}$ increases first and then decreases with the increase of the water content, and only the particle with $>10 \mathrm{~mm}$ increases always with increasing the water content. The optimal size distribution of the particles can be summarized as: about $50 \%$ particles with $>10 \mathrm{~mm}$, about $30 \%$ particles with 5-8 mm, about $10 \%$ particles with $8-10 \mathrm{~mm}$, and $10 \%$ other particles.

According to the measurements of moisture capacity and 
Table 7. Optimal water content for the five iron ores.

\begin{tabular}{|c|c|c|c|c|c|c|}
\hline Ore & & A & B & C & D & E \\
\hline Optimal water content & & 9.00 & 8.90 & 8.80 & 8.85 & 9.10 \\
\hline $\mathrm{R}^{2}$ & & 0.70 & 0.80 & 0.45 & 0.82 & 0.73 \\
\hline \multirow{3}{*}{$\begin{array}{c}\text { Fitting function in } \mathrm{Y}=\mathrm{B}_{1} \mathrm{x}^{2}+\mathrm{B}_{2} \mathrm{x}+\mathrm{c} \\
\mathrm{Y}: \mathrm{kPa} \mathrm{x} \text { : water content in } \%\end{array}$} & $\mathrm{~B}_{1}$ & -29.05 & -18.20 & -12.29 & -20.06 & -18.64 \\
\hline & $\mathrm{B}_{2}$ & 1.55 & 1.03 & 0.62 & 1.12 & 1.04 \\
\hline & $\mathrm{C}$ & 139 & 84.84 & 65.68 & 94.75 & 88.51 \\
\hline
\end{tabular}

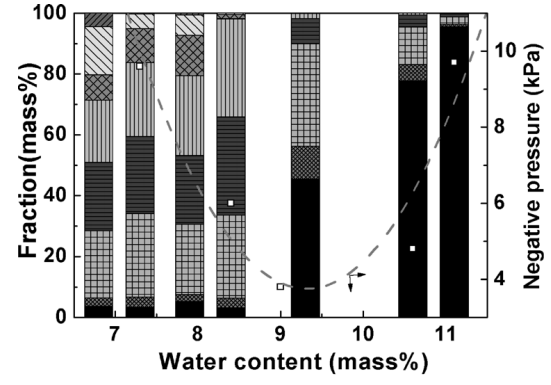

(a) Sample A

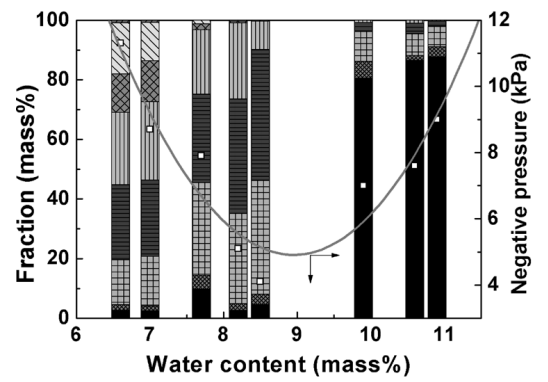

(d) Sample D

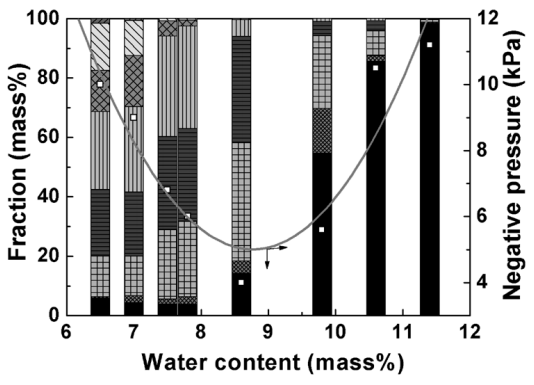

(b) Sample B

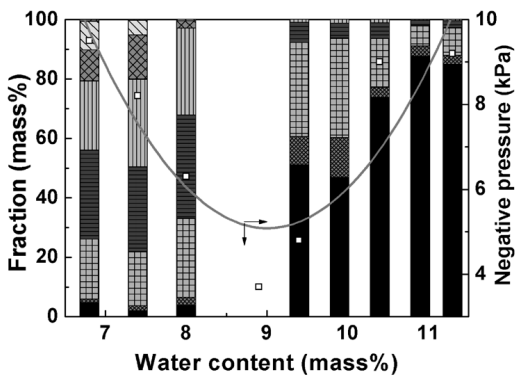

(e) Sample E

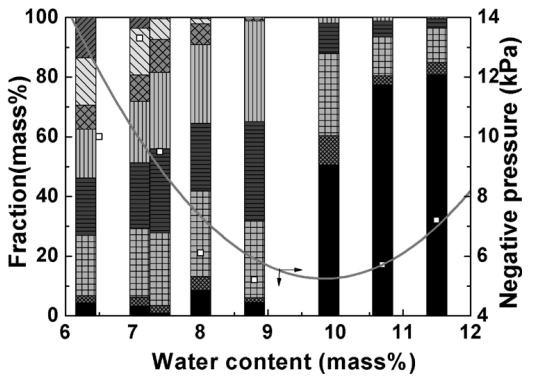

(c) Sample C

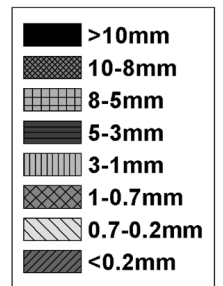

Fig. 11. Particle distribution of the granules verse water content for iron ores A-E.

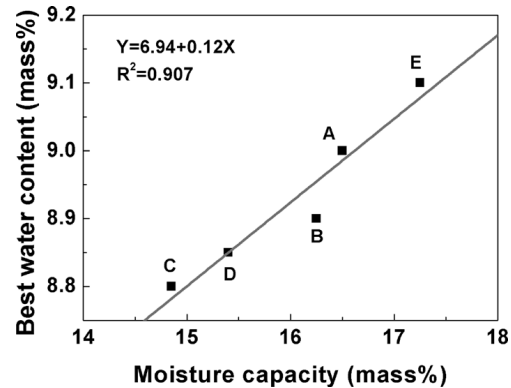

Fig. 12. Relationship between moisture capacity and best water content.

the optimal water contents, the relationship between these two parameters is shown in Fig. 12, from which it can be concluded that the mixture with higher moisture capacity need more water for getting a best permeability. The moisture capacity and the best water content have high positive correlation. The equation got in present study is:

$$
y=6.94+0.12 \times M c
$$

where $y$ is the optimal water content. The correlation coefficient of this equation is 0.907 . Using this equation, the optimal water content added into the mixture can be predicted.

\section{Conclusions}

In present study, moisture capacity of the iron ore particles was suggested, defined, and measured in a self-designed apparatus. The surface area and the pore features were measured. The moisture capacity of the iron ore was also applied on optimizing the granulation by finding the relationship between the moisture capacity of the mixture and the optimal water content. It was concluded as follows:

(1) The dependency of the moisture capacity on the external surface area and the pore volume was was expressed as $M c=13.7+0.374 \times S_{\mathrm{E}}-2896 \times V_{\text {pore }}$. The correlation agree swell with the measurements and indicate that the moisture capacity increase with increasing the external surface area of the iron ore, and decreases with increasing the pore volume in the iron ores.

(2) The moisture capacity and the optimal water content have high positive correlation. The iron ore which has high moisture capacity need more water added in the granulation process in order to get high permeability.

(3) The optimal size distribution of the granules after granulation is summarized as: about $50 \%$ particles with $>10 \mathrm{~mm}$, about $30 \%$ particles with $5-8 \mathrm{~mm}$, about $10 \%$ particles with $8-10 \mathrm{~mm}$, and $10 \%$ other particles.

(4) The correlation got by the measurements: $y=6.92+$ $0.12 \times M c$ can be used to predict the optimal water content in the granulation.

\section{Acknowledgments}

The authors are especially grateful to Chongqing University Graduates' Science and Innovation Fund (Grant No. 200911B1A0120328) and Key Project of Chinese National Programs for Fundamental Research and Development (Grant No. 2007CB613503). 
ISIJ International, Vol. 50 (2010), No. 5

\section{REFERENCES}

1) D. M. Newitt and J. M. Conway-Jones: Trans. Inst. Chem. Eng., 36 (1958), 422.

2) H. Rumpf: Agglomeration, Interscience, Pennsylvania, (1962), 379.

3) P. C. Kapur: Adv. Chem. Eng., 10 (1978).

4) W. Pietsch and H. Rumpf: Ingenieur Technik, 39 (1967), No. 15 885 .

5) H. Schubert: Powder Technol., 11 (1975), No. 2, 121.

6) S. M. Iveson, S. Holt and S. Biggs: Colloids Surf. A: Physicochemical and Engineering Aspects, 166 (2000), 203.

7) S. M. Iveson, S. Holt and S. Biggs: Int. J. Miner. Process., 74 (2004), 281.

8) S. M. Iveson, K. F. Rutherford and S. Biggs: Trans. Inst. Min. Metall. C, 110 (2001), C113.

9) P. C. Kapur: Adv. Chem. Eng., 10 (1978), 55.
10) J. D. Litster and A. G. Waters: Powder Technol., 55 (1988), 141.

11) J. Litster, B. Ennis and L. Lian: The Science and Engineering of Granulation Processes 15th ed., Particle Technology Series, ed. by B. Scarlett, Kluwer Academic Publishers, Dordrecht, (2004), 247.

12) D. H. Lister and F. P. Glasser: Trans. Br. Ceram. Soc., (1967), 293.

13) X. Lv, C. Bai, C. Zhou and H. Xie: Proc. of the 5th Int. Cong. on the Science and Technology of Ironmaking, Shanghai, (2009), 235.

14) L. L. Schramm: The Language of Colloid and Interface Science, ed. by ACS Professional Reference Book, ACS, Washington, DC., (1993), 129.

15) S. Kondo, T. Ishikawa and I. Abe: Adsorption Science (In Japanese), Maruzen, Tokyo, (1991), 68.

16) J. Khosa and J. Manuel: ISIJ Int., 47 (2007), No. 7, 965

17) M. Yoshinaga, S. Sato and T. Kawaguchi: Australia Japan Extractive Metallurgy Symp., Sydney, (1980), 145. 